\title{
Combining Existing Monitoring Sites with a Probability Survey Design—Examples from U.S. EPA's National Coastal Assessment
}

\author{
John F. Paul ${ }^{1, *}$, Henry A. Walker ${ }^{2}$, Walter Galloway ${ }^{2}$, Gerald Pesch $^{2}$, Donald Cobb ${ }^{2}$, Charles J. \\ Strobel $^{2}$, J. Kevin Summers ${ }^{3}$, Michael Charpentier ${ }^{4}$ and James Heltshe ${ }^{5}$
}

\author{
${ }^{I}$ National Health and Environmental Effects Research Laboratory, U.S. Environmental Protection Agency, Mail Drop \\ B343-06, Research Triangle Park, NC 27711 USA; ${ }^{2}$ Atlantic Ecology Division, EPA, Narragansett, RI 02882 USA; \\ ${ }^{3}$ Gulf Ecology Division, EPA, Gulf Breeze, FL 32561 USA; ${ }^{4}$ Computer Sciences Corporation, Narragansett, RI 02882 \\ USA and ${ }^{5}$ Department of Statistics, University of Rhode Island, Kingston, RI 02881 USA
}

\begin{abstract}
U.S. Environmental Protection Agency's (EPA's) National Coastal Assessment was envisioned as a research effort led by EPA's Office of Research and Development to evaluate assessment methods for ecosystem condition monitoring. The program was conducted through strategic partnerships with the coastal states. These states conducted the survey in their waters with a common set of indicators. The resources targeted for initial monitoring were estuarine waters. A flexible probability survey design was used to incorporate, to the extent possible, existing state monitoring program sites. Three criteria were developed to evaluate existing monitoring program sites in the northeastern United States for possible incorporation into the national design: (1) the sites were selected to be representative, (2) the variables sampled at the sites were similar in distribution with variables from a probability design, and (3) the correlation structure of variables was equivalent to that for a probability design. Detailed examples were presented for Long Island Sound water quality sites, New Jersey coastal water quality sites, and Casco Bay, ME, sediment sites to illustrate the approach.
\end{abstract}

Key Words: Survey data, probability samples, estuaries.

\section{INTRODUCTION}

A continuing issue for the design of environmental monitoring programs is the possible incorporation of existing monitoring program sites into probability survey designs. The statistical survey community is not in agreement that it is even possible to incorporate nonprobability sites into a probability design. Ideally, over the long-term (10 years or so) and with the current understanding of sampling designs, a national program would consist entirely of probabilitybased monitoring designs at all levels [1]. Then the issues would be how the different probability designs would be combined to produce regional and national estimates and to what extent the probability designs would need to be augmented with targeted (nonprobability) sites for needs that could not be addressed with a probability design. The existing monitoring sites would be considered as a transition issue, how to get to the long-term vision. For the short term, the major objectives of the probability-based program and the existing programs need to be considered.

Many existing monitoring programs are based on targeted station designs (sites selected for an important purpose at the initiation of the monitoring but not randomly selected); these existing programs represent a tremendous investment of fiscal resources and contain a wealth of potentially valu-

*Address correspondence to this author at the National Health and Environmental Effects Research Laboratory, U.S. Environmental Protection Agency, Mail Drop B343-06, Research Triangle Park, NC 27711 USA; Tel: 919-541-3160; Fax: 919-541-4621; E-mail: paul.john@epa.gov able environmental information. Probability surveys often have been used to address significant questions facing environmental managers. For example, section 305(b) of the Clean Water Act requires the states, tribes, and territories to report on the percent of their jurisdictional surface waters that are impaired [2]. The quandary facing resource managers on whether to participate in a probability survey is what to do with existing monitoring sites when the new monitoring requirements lead them to a probability-based design. If they completely replace the existing sites, they lose the immediate ability to track trends, whereas, if they use existing sites, they may not be able to make inferences about the condition of their total resource from these sites. Probability surveys have been noted as the dominant design for national terrestrial monitoring programs, whereas directed site selection (nonprobability) is the dominant design for national aquatic resource monitoring programs [3]. This implies that the dilemma is more of an issue for aquatic resource managers.

Over the past few years, there has been a growing literature on combining nonprobability and probability sites [4-8]. Some insight into characterizing a population by combining nonprobability samples with probability samples has been provided by Overton et al. [6] and summarized by Cox and Piegorsch [5]. A probability sample is designed to characterize a clearly defined population of interest, such as an ecological resource, over a clearly defined geographic area. The nonprobability sample should be identified with a subset of this population. The population then can be partitioned so 
that the test for representativeness of the nonprobability sample is made with this subset. To complete characterization of the whole population, the nonprobability sample partition subsequently would be combined with the probability sample partition. Overton et al. [4] suggest that similarity is a reasonable criterion for the nonprobability sample to be treated as representative. Here, we take similarity to mean that the two sets of sites have at least one indicator in common, and that the two distributions for the indicators are indistinguishable. The Kolmogorov-Smirnov test [7] can be used to determine the latter. As pointed out by Cox and Piegorsch [5], the issue of representativeness can be extremely difficult to prove for a nonprobability site, although it may be quite easy to disprove.

The purpose of this paper is to describe the approach used to evaluate existing state estuarine monitoring program sites to determine if they possibly could be used in a national probability design. The approach and examples are from the northeastern U.S. implementation of the National Coastal Assessment (NCA).

\section{DATA AND METHODS}

\section{National Coastal Assessment}

The U.S. Environmental Protection Agency's (EPA's) NCA was envisioned as a partnership effort organized by EPA's Office of Research and Development (ORD) with EPA's Office of Water and regional offices, natural resource agencies in 24 states and one commonwealth, selected academic institutions, the National Oceanic and Atmospheric Administration, and the U.S. Geological Survey to evaluate the assessment methods ORD had developed for ecosystem condition monitoring for coastal systems [8]. This program surveyed the condition of the nation's coastal resources by creating an integrated, comprehensive coastal monitoring program to assess coastal ecological condition. The program initially was focused on estuarine waters.

The strategy for NCA focused on strategic partnerships with all 24 U.S. coastal states and Puerto Rico. Using a flexible, probability survey design and a common set of survey indicators (measures), each state conducted the survey in their waters, with, in some circumstances, assistance from academic institutions and federal agencies, and assessed the condition of their coastal resources. These estimates have been aggregated to assess condition at the EPA regional, biogeographical, and national levels [8]. The primary partnerships for the execution of the surveys were the state resource agencies and organizations responsible for monitoring coastal resources. To effectively partner with the states in this national program, it was important that, to the extent technically possible, to incorporate existing state monitoring sites into the overall national design. In some cases, states have a large investment in monitoring data from their sites that have been providing an ongoing benchmark for the condition of their waters. The possible incorporation of their existing sites into a program such as NCA would save fiscal resources (states already were visiting the sites and have only to add collection of additional information at each site) and provides the states with assistance in building their monitoring infrastructure (i.e., provides an opportunity to try out different designs and indicators).

\section{Background on Probability Sampling as Applied in NCA}

Probability sampling is based on a randomized selection of sampling sites. A probability sample is selected in an explicit manner that allows statements to be made for estimates of the statistical population from which it was selected [6], whereas a targeted, or fixed, site is one for which no probability basis for selection of that site is apparent. Two key characteristics of a probability sample are that (1) the probability of obtaining any element of the statistical population is known (this implies a definition of the statistical population of interest), and (2) the inclusion probability of any sample of the population is positive, that is, all samples have a known probability of being included $[9,10]$. The inclusion probability of any element is defined as the probability with which the element is included in the statistical population.

An important feature of probability sampling is the ability to make inferences about the target population from the finite number of sampling sites. The basis for this is the requirement that every sampling element in the sampled population has a non-zero probability of being selected $[9,10]$. The probability sample provides an unbiased estimate (given the appropriate estimator), meaning that the expected value of the parameter of interest approaches the true value as the sample size increases (as variance decreases). Whereas, bias will not be eliminated with increasing sample size [11].

The probability sampling design implemented in NCA is a stratified random sample. Stratification reduces the variance component within each stratum because elements within the stratum are more similar to one another than they are to the population as a whole. Hence, combining the information from strata into an estimate for the total population provides a more precise estimate if indeed the population is truly stratified [12]. The target population is the set of population elements about which inferences will be made. The sampled population is the set of elements directly available for measurement.

\section{Target Population}

The monitoring program needs to have clearly stated objectives for which data are to be collected and analyzed. For the initial implementation of NCA, the objectives were to

(1) assess the health or condition of U.S. estuarine waters and track changes in that condition through time, and

(2) assess the health or condition of individual states' estuarine waters and track changes in that condition through time.

From these objectives, the target population was clearly the estuarine waters of the individual states and the entire United States.

A data quality objective (DQO) is a statement identifying the anticipated use of environmental data leading to a decision or action to be taken and defining the level of uncertainty one is willing to accept in the data supporting the decision or action, expressed in quantitative, statistical terms [13]. The target DQO for the NCA program was to characterize the condition of estuaries or other coastal entities as a proportion of areal extent by parameter or by index for re- 
gional and national estimates within $\pm 10 \%$ for any year and within $\pm 10 \%$ for any state every two years [14].

In the development of the sampling frames (the material used to describe the population units \{e.g., maps of estuarine boundaries \}) for the Environmental Monitoring and Assessment Program (EMAP)-Estuaries program in the early 1990s, the estuarine boundaries for the East Coast were developed using U.S. Geological Survey 1:100K digital line graphs and the above definition for estuarine waters. Because there were some judgments employed in setting the upper and outer boundaries, the early discussions with the states in the planning for NCA included the locations of these boundaries. The boundaries were appropriately adjusted to coincide with the boundaries in use by the state resource agencies. For example, some of the upper boundaries in Maine were adjusted to coincide with the upstream extent of salt (salinity approximately $1 \mathrm{o} / \mathrm{oo}$ ), and some outer boundaries were adjusted according to their management needs. The adjustments of upper boundaries represent an insignificant change of the statistical population. The outer boundary changes represent exchange of area with the coastal waters component target population.

\section{Strata or Sampling Classes}

Stratification, or division of the target population into strata, makes use of prior information on the characteristics of the target population to divide it into strata [12]. Samples are allocated to each stratum, which is the primary focus for study with the desired level of certainty (i.e., samples are allocated to obtain the desired uncertainty in the estimates). Results for the entire population are obtained by appropriate combination of strata results.

The sampling strata for NCA were the coastal biogeographic provinces [15] used in the EMAP-Estuaries program [16]. There are 13 provinces for the entire United States. Where partnerships have been developed with the states, state-level strata are used. Within each state, sampling classes are used to allocate the available sample sites. The target number of sites for each stratum is 70 per year for regional and national estimates and 70 to 80 over 2 years of sampling for state-level estimates. These numbers were chosen based on experience with the EMAP-Estuaries program [17] to meet target data quality objectives.

Sampling classes within state strata are determined by areas of concern identified by the state resource managers. We met with the state resource managers to determine the sampling classes that would be most useful for their management needs. The available samples ( 70 to 80 per state over 2 years) then were allocated proportionally across the sampling classes at the discretion of the state managers. For example, the sampling classes in Long Island Sound were (1) the open waters of the sound, where water quality is of major concern, and (2) the harbors and embayments around the edges of the sound, where toxic contamination in the sediments is of concern. Approximately 40 samples were allocated to the open water and 40 samples to the harbors and embayments (20 each in New York and Connecticut).

\section{Spatial Distribution of Samples}

A common occurrence in random sampling over a spatial area is the clumping of samples. Spatially distributing the samples is desirable in environmental monitoring to provide for a more appropriate characterization of the target population. In many cases, it provides more accurate estimates of statistical quantities, such as mean and variance [12]. One way to achieve an adequate spatial distribution is to use a grid overlay $[18,19]$. A random sample then is selected for each grid cell; the size of the grid cell, or the number of them, is determined by the number of samples to be allocated.

For the northeastern U.S. implementation of NCA, the random point in the grid was restricted to the estuarine resource (sampled population) within the grid cell. This implementation of the design associates with each sample a variable weighting factor (hence, variable inclusion probability) proportional to the fraction of the grid cell that is estuarine resource (i.e., water). These weighting factors are used when estimates are made for mean and variance of measurement values (indicators).

\section{Possible Incorporation of Existing Monitoring Program Sites into NCA Design}

Before we evaluate sites for incorporation into the probability design, data collected from existing monitoring program sites must meet the quality assurance protocols specified by the program. This is to ensure that the statistical inferences made from these data are not compromised. Once this has been done, the evaluation of the site selection can proceed.

If existing monitoring program sites were selected using a probability design, then they can be incorporated directly into the NCA design. For example, some state fish trawl programs use a stratified random design for site selection, with stratification usually based on depth and habitat. Cox and Piegorsch [5] discuss procedures for combining the samples collected from different probability designs. However, a comparison needs to be made between the target population of the stratified random design and the target population for NCA. If the existing program does not include all of the NCA target population, then it would need to be supplemented with additional sample sites over the remainder of the target population.

For existing monitoring program sites that were not selected using a probability design, the process to determine if sites could be incorporated into the NCA design was based on the two concepts identified in Overton et al. [4]:

(1) the sites can be identified with a subset of the population, and

(2) the sites are similar to a probability sample of the same subset of the population.

These concepts were converted into criteria that were used to evaluate if the existing monitoring sites could be considered for incorporation into the NCA design. The three criteria, applied in a sequential fashion, were as follows.

(1) The sites must have been selected initially to be representative of the area from which they were selected. For example, sites that do not satisfy this criterion would include those targeted for an outfall discharge location, the end of a dock, or a bridge overpass (for convenience in acquiring samples). 
(2) The variables sampled at the existing monitoring sites are similar in distribution with variables from a probability design for the same subset of the statistical population. For example, cumulative distribution functions (CDFs) of bottom dissolved oxygen concentration can be compared. A CDF displays the estimated portion of the population above and below any specified value of the variable. This criterion requires that data from a probability design be available for the subset of interest.

These two criteria were required to be met before the existing sites are determined to be acceptable for incorporation into the design. Because of the limited availability of existing probability data for multiple variables, a third criterion was considered as confirmatory but was not required.

(3) The correlation structure of variables from the existing monitoring sites is equivalent to that from a probability design for the same subset of the statistical population.

This criterion requires that information on multiple variables from the probability design be available for the subset of interest. It is tested only if first and second criteria are met.

The first two criteria determine whether there is any potential bias in using the existing sites and looks at how individual variables are distributed. The third criterion determines how the variables change with one another. So, we can never prove that existing sites are truly representative because our logic tests are set up to disprove the null hypothesis. The best we can achieve is that the existing site data look as if they were drawn from a probability sample.

\section{RESULTS}

Some state monitoring sites that were considered suitable for incorporation into the northeastern U.S. implementation of NCA are presented in Table 1. An example of each is discussed.

\section{Long Island Sound Water Quality}

The Long Island Sound Study (LISS) water quality monitoring program, conducted through the Connecticut Department of Environmental Protection's Long Island Sound Ambient Water Quality Monitoring Program [20], supports the monitoring plan of the Comprehensive Conservation and
Monitoring Plan for the Sound [21]. The monitoring program included 18 year-round sites and 30 summer-only sites. Variables measured included nutrients (year-round sites only), chlorophyll $a$, total suspended solids, temperature, salinity, and dissolved oxygen. The year-round sites were selected to be representative of the open water areas along the axis of the sound (14 stations to capture the east-west gradient in water quality parameters) and of the lateral variability in the open water areas (4 stations along two crosssections, one in the western basin and one in the central ba$\sin )$. These stations were monitored to collect data in support of the water quality modeling activities in the sound. The summer-only sites were added in 1994 and were selected to determine the areal and temporal extent of low dissolved oxygen conditions in the Sound [20]. Based on this information, both the year-round and summer-only sites were deemed to satisfy the first criterion for inclusion.

To evaluate the second criterion, CDFs of depth were compared with data collected for LIS by the EMAPVirginian Province project during 1990 to 1993 with a probability sampling design [22, 23, 17]. The weighting factors for the LISS sites were assigned by generating Thiessen polygons [24] for the existing sites and using the area of the polygons as the weight. Only depths could be compared directly because the probability data and the combined LISS site data were not available for overlapping years. However, we did look at CDFs for salinity, temperature, and dissolved oxygen.

The year-round sites deviated from the EMAP- Virginian Province distribution for depths by an approximate $+5-\mathrm{m}$ offset (Fig. 1). These sites were selected to be representative of the deeper water portions of the sound and underrepresent the shallower areas of the open-water portion of the sound. Combining the summer-only sites with the yearround sites gives a distribution similar to the probability sites. This agreement was interpreted to fulfill the second criterion for inclusion.

The third criterion was evaluated by comparing correlation matrices (Spearman's rank correlation) for four variables $(\{1\}$ bottom temperature, $\{2\}$ salinity, $\{3\}$ dissolved oxygen, and $\{4\}$ depth) from the EMAP-Virginian Province sampling during 1990 to 1993 with the LISS data from 1994 to 1996 . Equality of correlation matrices was tested using the procedure in Morrison [25]. The matrices for the LISS corre-

Table 1. Summary of Existing Monitoring Sites Evaluated and Considered Acceptable for Incorporation into Northeastern U.S. Implementation of the NCA Design

\begin{tabular}{|c|c|c|c|c|}
\hline $\begin{array}{c}\text { State Monitoring } \\
\text { Program Sites }\end{array}$ & Reference & $\begin{array}{c}\text { Probability } \\
\text { Samples }\end{array}$ & $\begin{array}{c}\text { Representative } \\
\text { Sites }\end{array}$ & $\begin{array}{c}\text { Variance } \\
\text { Structure }\end{array}$ \\
\hline \hline Casco Bay sediment sites & TAMU 1992 [28] & No & Yes & Depth \\
\hline $\begin{array}{c}\text { Long Island Sound water } \\
\text { quality sites }\end{array}$ & $\begin{array}{c}\text { U.S. EPA 1994 [21], } \\
\text { State of CT 2000 [20] }\end{array}$ & No & Depth & NA $^{1}$ \\
\hline $\begin{array}{c}\text { New Jersey DEP ambient } \\
\text { monitoring sites }\end{array}$ & $\begin{array}{c}\text { NJDEP 1996 [27], } \\
\text { Korndeifer 1998 [26] }\end{array}$ & No & Yes & $\begin{array}{c}\text { Temperature, } \\
\text { salinity, dissolved oxygen }\end{array}$ \\
\hline
\end{tabular}

${ }^{1} \mathrm{NA}=$ Not available.

${ }^{2}$ Long Island Sound Study data from 1994, 1995, and 1996 compared with EMAP-Virginian Province Long Island Sound 1990-1993.

${ }^{3}$ New Jersey Department of Environmental Protection data from 1990 and 1993 compared with EMAP-Virginian Province New Jersey Coastal $1990-1993$. 


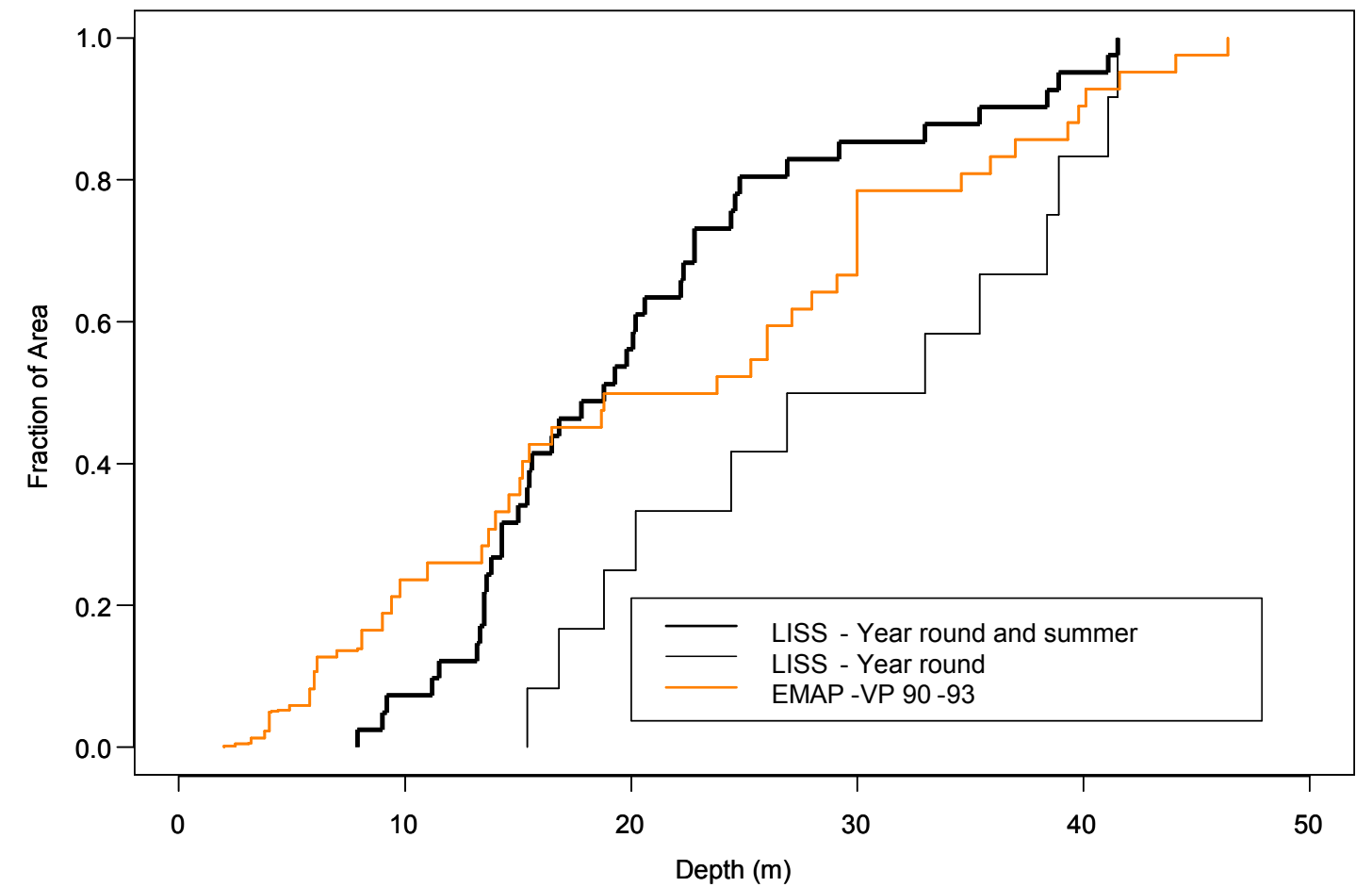

Fig. (1). Cumulative distribution functions for depth from Long Island Sound Study (LISS) and EMAP-Virginian Province (EMAP-VP) Long Island Sound sites.

lations from the individual years 1994, 1995, and 1996 all were significantly different from each other and, with the exception of 1994, were different from the EMAP-Virginian Province correlation matrix (evaluated at a 0.05 significance level). However, the LISS pooled correlation matrix was not significantly different from the EMAP-Virginian Province 1990 to 93 correlation matrix (Table 2). The results of evaluating the three criteria indicate that the combined set of LISS sites could be incorporated into the design and treated as probability sites representative of the open water portion of Long Island Sound by using Thiessen polygons to generate appropriate weighting factors.

\section{New Jersey Coastal Water Quality}

The New Jersey Department of Environmental Protection (NJDEP) has implemented a water quality monitoring program in coastal estuaries since 1989 to provide basic measures of the ecological health of New Jersey's coastal waters [26]. Approximately 200 sites were monitored four times per year. The sites were chosen initially to be representative of (1) a major body of water, (2) fresh water inputs into an estuary, (3) water being exported from an estuary to the ocean, or (4) water quality in the vicinity of an ocean outfall [27]. The first three reasons were deemed adequate to satisfy the first criterion for selection.

The distributions of salinity, temperature, and dissolved oxygen, were compared to the EMAP-Virginian Province data for coastal New Jersey, similar to what was done for Long Island Sound (Fig. 2). The NJDEP data were available from August 1990 and 1993. The sites all were weighted equally for construction of the CDFs because of the large number of samples (146 in 1990 and 112 in 1993). Given the uncertainty associated with the distribution for the small number of sites from the EMAP-Virginian Province, the
NJDEP distributions were deemed indistinguishable from the probability sites and, hence, satisfied the second criterion for inclusion.

To evaluate the third criterion, the correlation matrices (Spearman's rank correlation) for the three variables were compared. Equality of matrices was tested with Morrison's procedure [25]. The correlation matrices for the NJDEP data were different for 1990 and 1993 (evaluated at the 0.05 significance level). The NJDEP individual-year and the pooled correlation matrices were not significantly different from the EMAP-Virginian Province coastal New Jersey data for 1990 to 1993 (Table 3). Based on the results of the three criteria evaluations, the NJDEP sites were considered acceptable for incorporation into the NCA design.

\section{Casco Bay Sediments}

The Casco Bay National Estuary Program collected surficial sediments at 65 sites in 1991 for a comprehensive inventory of sediment contaminants in the bay [28]. The bay was divided into five regions based on geology. Using historical information, sites were selected to provide good areal coverage, sample surface sediments of different ages, and representative coverage of benthic communities. This was taken to be sufficient to satisfy the first criterion.

Because no probability data were available from Casco Bay for which to make comparisons, a different procedure was used to develop probability-based depths. The systematic grid for NCA was used to select random sample sites in Casco Bay. Using depth charts, depths were "sampled" at each site. This distribution of depths was compared with the depths at existing Casco Bay sediment sites randomly selected within each of the grid cells. Results indicated similarity of distributions (Fig. 3). Because of the sampling design, the third criterion could not be evaluated. Based on this in- 
Table 2. (a) Correlation Matrices (Spearman's Rank Correlation) for Bottom Temperature, Salinity, Dissolved Oxygen, and Depth Data for the Long Island Sound Study (LISS) Water Quality Monitoring Program (1994, 1995, and 1996) and EMAP-Virginian Province Long Island Sound (EMAP-VP; 1990-1993). (b) Results of test for Equality of Correlation Matrices Using the Procedure in Morrison (1976) $(p=0.05)$

(a)

\begin{tabular}{|c|c|c|c|}
\hline \multicolumn{4}{|c|}{ LISS - $1994(\mathrm{~N}=38)$} \\
\hline Salinity & 0.42 & 1.00 & 0.68 \\
\hline \multicolumn{4}{|c|}{ LISS - $1995(\mathrm{~N}=41)$} \\
\hline Temperature & 1.00 & -0.71 & 0.06 \\
\hline Salinity & -0.71 & 1.00 & 0.44 \\
\hline Dissolved oxygen & 0.06 & 0.44 & 1.00 \\
\hline Salinity & 0.31 & 1.00 & 0.80 \\
\hline Dissolved oxygen & 0.65 & 0.80 & 1.00 \\
\hline \multicolumn{4}{|c|}{ LISS - Pooled } \\
\hline Temperature & 1.00 & 0.01 & 0.41 \\
\hline Salinity & 0.01 & 1.00 & 0.64 \\
\hline Dissolved oxygen & 0.41 & 0.64 & 1.00 \\
\hline \multicolumn{4}{|c|}{ EMAP-VP 1990-1993 $(\mathrm{N}=37)$} \\
\hline
\end{tabular}

(b)

\begin{tabular}{|c|c|c|c|c|}
\hline & LISS - 1994 & LISS - 1995 & LISS - 1996 & LISS - pooled \\
\hline \hline LISS - 1995 & Different & & & \\
\hline LISS - 1996 & Different & Different & Different & Not different \\
\hline EMAP-VP 1990-1993 & Not different & Different & & \\
\hline
\end{tabular}

formation, the sediment sites were accepted as appropriate to incorporate into the NCA design.

\section{SUMMARY}

To effectively partner with the states in the implementation of NCA, it was important to use an overall design with the flexibility to incorporate, to the extent possible, existing state monitoring program sites. However, a requirement for the NCA design was that sites be probability-based, a requirement that was necessary to meet the objectives of the program. Incorporation of state monitoring sites that were probability-based (e.g., stratified random samples) was straightforward. Using the concepts introduced by Overton et al. [4] for combining nonprobability samples with probability samples, criteria were developed for evaluating existing nonprobability sites for possible incorporation into the NCA design. 

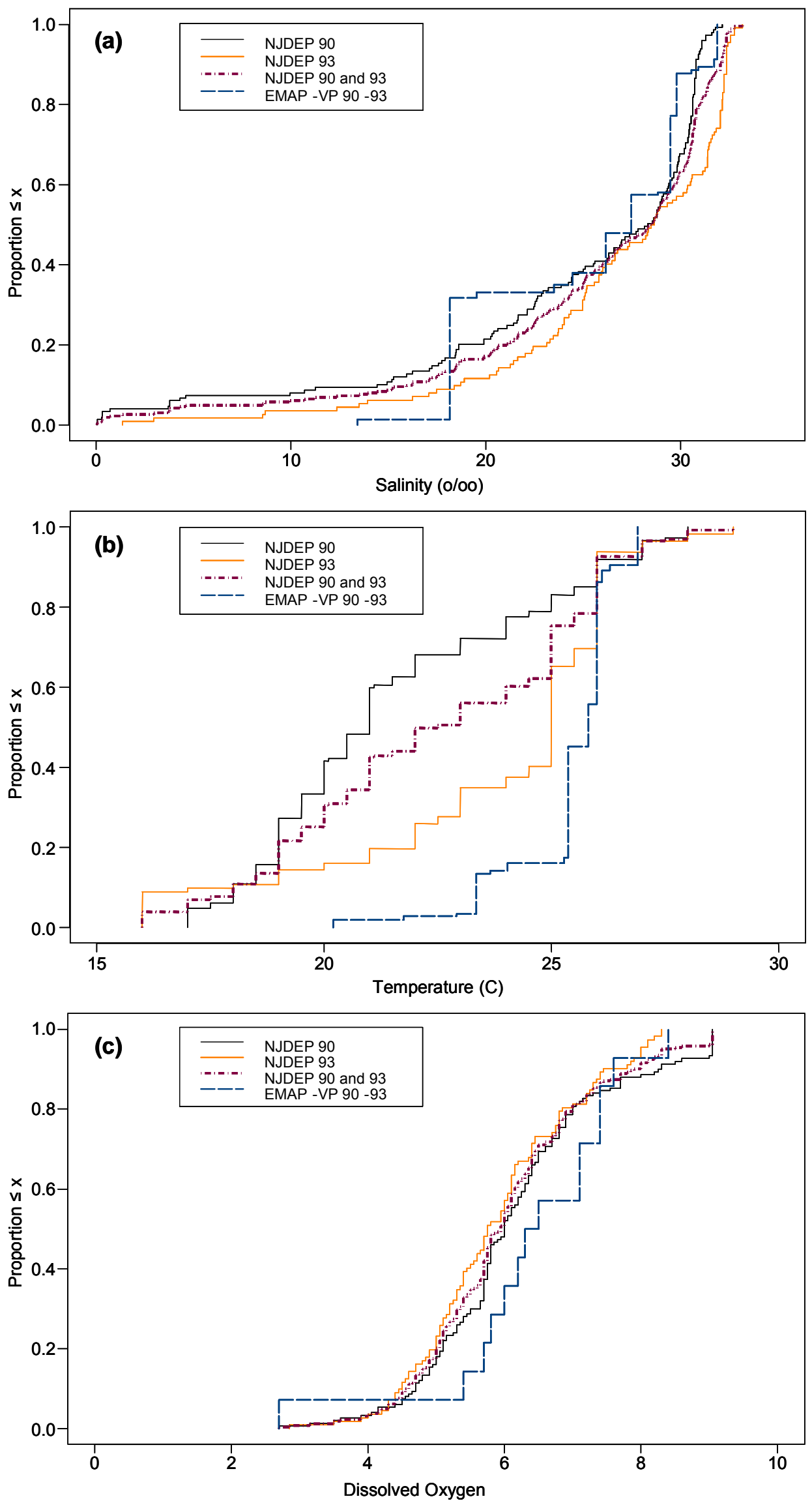

Fig. (2). Cumulative distribution functions for data from New Jersey Department of Environmental Protecton (NJDEP) and EMAP-Virginian Province (EMAP-VP) New Jersey coastal sites. (a) Salinity. (b) Temperature. (c) Dissolved oxygen. 
Table 3. (a) Correlation Matrices (Spearman Rack Correlation) for Temperature, Salinity, Dissolved Oxygen, and Depth Data for the New Jersey Department of Environmental Protection (NJDEP) Ambient Monitoring Program (1990 and 1993$)$ and the EMAP-Virginian Province (EMAP-VP) Coastal New Jersey Systems (1990-1993). (b) Results of test for Equality of Correlation Matrices Using the Procedure in Morrison $(1976)(p=0.05)$

(a)

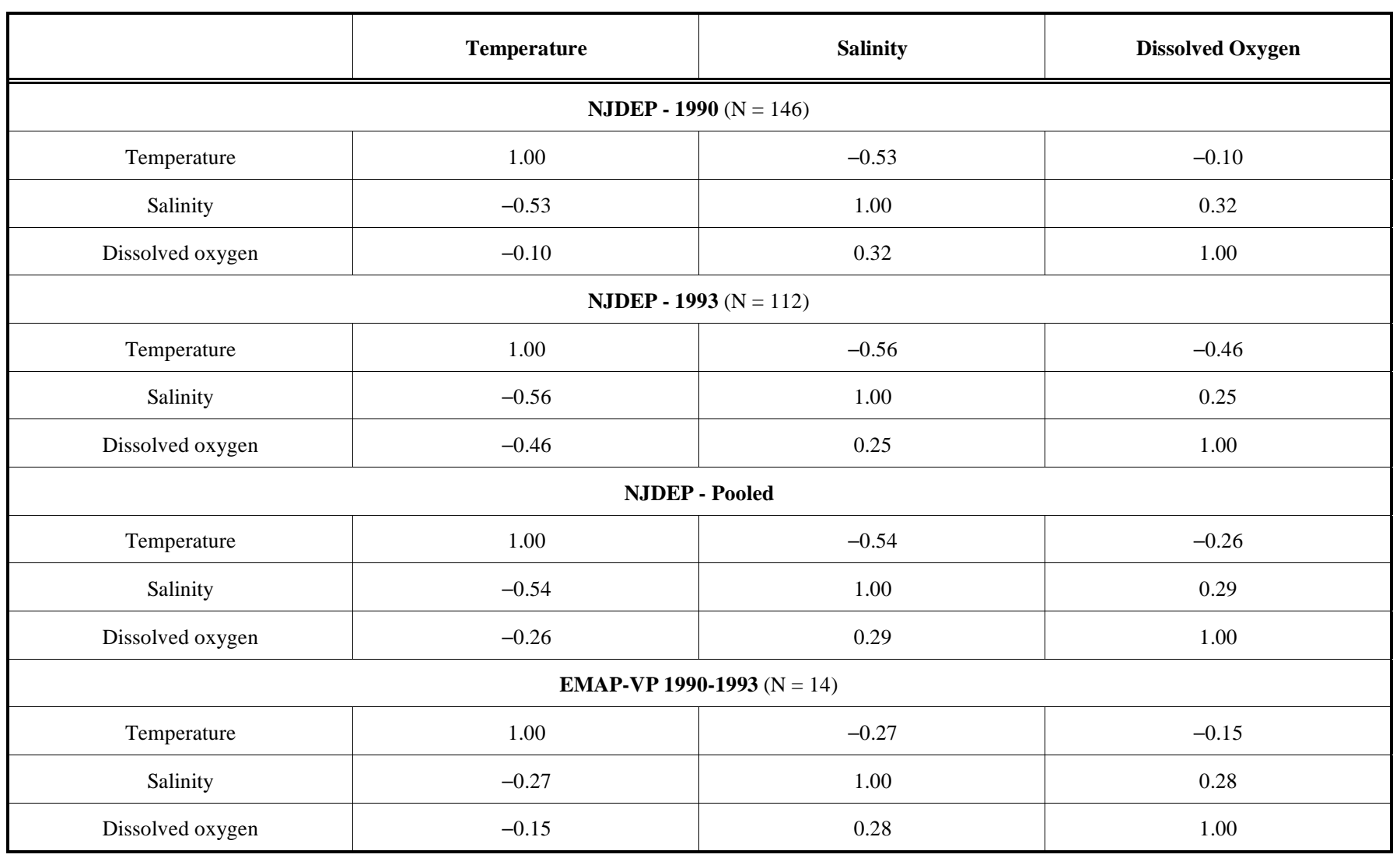

(b)

\begin{tabular}{|c|c|c|c|}
\hline & NJDEP - 1990 & NJDEP - 1993 & NJDEP - Pooled \\
\hline \hline NJDEP - 1993 & Different & & Not different \\
\hline EMAP-VP 1990-1993 & Not different & Not different \\
\hline
\end{tabular}

The states of Massachusetts, Rhode Island, and Connecticut conduct fish trawl surveys using stratified random samples. These program sites were incorporated directly into the NCA design. Existing targeted monitoring program sites from Maine, Long Island Sound, New York, New Jersey, and the Delaware estuary were evaluated against the criteria for possible incorporation. Each location required a slightly different procedure for determining the distribution for comparison with probability data. These existing state program sites satisfied the first two criteria, and some satisfied the third (optional) criterion. The sites were considered acceptable for incorporation into the NCA design. We obviously had to have a form of probability data for comparison purposes. One definite limitation to the evaluation of the criteria is that the comparison of distributions for the second criterion often was limited to depth data.

\section{ACKNOWLEDGEMENTS}

Thanks to Edward Dettmann, William Nelson, Anthony Olsen, Donald Stevens, Steve Schimmel, Chad Cross and anonymous reviewers for their critical reviews of this paper. These reviewers were not all in agreement on the basic philosophical view presented in this paper: that it is possible to incorporate nonprobability samples into a probability survey. Discussion with Denis White (EPA, Corvallis) spawned the third criterion. We thank John Barton for technical editing and formatting. The research described in this paper has been funded, wholly or in part, by EPA. This paper has not been subjected to Agency review; therefore, it does not necessarily reflect the views of the Agency. This is contribution no. AED-00-095 of the Atlantic Ecology Division, National Health and Environmental Effects Research Laboratory. 


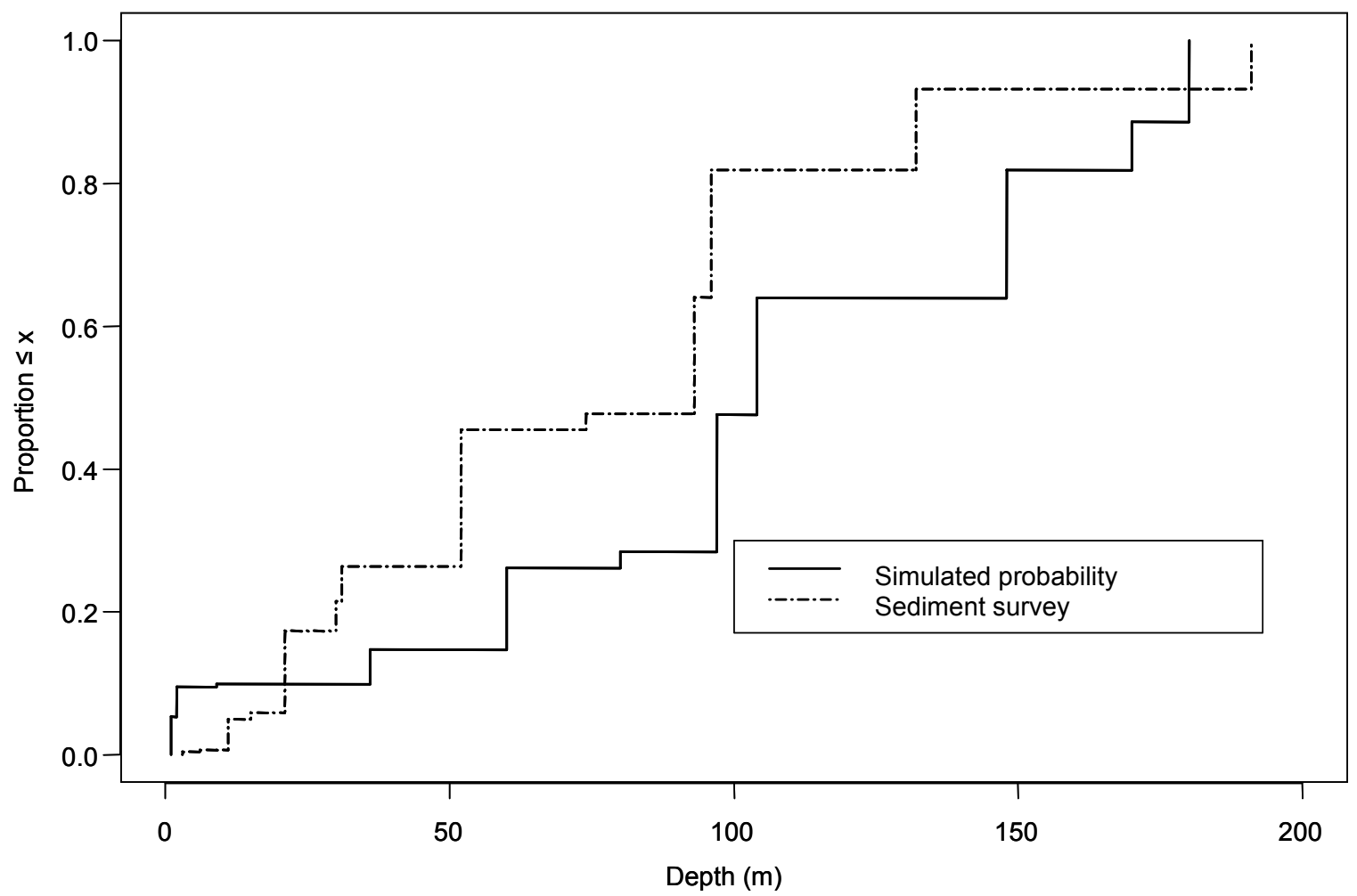

Fig. (3). Cumulative distribution functions for depth from Casco Bay sediment survey and simulated probability sites.

\section{REFERENCES}

[1] U.S. EPA. The importance of switching to probability surveys for aquatic monitoring programs. Retrieved 19 February 2008 from www.epa.gov/nheerl/arm

[2] U.S. EPA. National water quality inventory: 2000 report. EPA-841R-0-2001. U.S. EPA Office of Water, Washington, DC 2000.

[3] Olsen AR, Sedransk J, Edwards D, et al. Statistical issues for monitoring ecological and natural resources in the United States. Environ Monit Assess 1999; 54: 1-45.

[4] Overton JM, Young TC, Overton WS. Using "found" data to augment a probability sample: procedure and case study. Environ Monit Assess 1993; 26(1): 65-83.

[5] Cox LH, Piegorsch WW. Combining environmental information. I: Environmental monitoring, measurement and assessment. Environmentrics 1996; 7: 299-308.

[6] Overton WS. A strategy for use of found samples. Technical Report 139. Department of Statistics, Oregon State University, Corvallis, Oregon 1990.

[7] Venables WN, Ripley BD. Modern applied statistics with S-Plus. Springer, New York 1997

[8] U.S. EPA. National coastal condition report. U.S. EPA, Offfice of Research and Development and Office of Water, Washington, DC 2001.

[9] Cochran WG. Sampling techniques. John Wiley \& Sons, New York 1977.

[10] Overton WS. Probability sampling and population inference in monitoring programs. In: Goodchild MF, Parks BO, Steyaert LT, Eds. Environmental modeling with GIS. Oxford University Press, New York 1993; pp. 470-80.

[11] Draper D, Bowater R. Sampling errors under non-probability sampling. In: Bowater R, Chambers C, Davies P, et al. Eds. Model quality reports in business statistics: theory and methods for quality evaluation. Eurostat, Luxembourg 1999; Chapter 4.

[12] Gilbert RO. Statistical methods for environmental pollution monitoring. Van Nostrand Reinhold Company, New York 1987.

[13] Olsen AR. Program data quality objectives for EMAP status and trends. Draft report. U.S. EPA, Environmental Research Laboratory, Corvallis, OR 1992.
[14] U.S. EPA. National coastal assessment strategy. Draft report. U.S. EPA, Research Triangle Park, NC 2000.

[15] Terrell TT. Physical regionalization of coastal ecosystems of the United States and its territories. FWS/OBS-79/80. Office of Biological Services, U.S. Fish and Wildlife Service 1979.

[16] Holland AF, Ed. Near coastal plan for 1990: Estuaries. EPA 600/490/033, Office of Research and Development, U.S. EPA, Narragansett, RI 1990.

[17] Paul JF, Gentile JH, Scott KJ, et al. EMAP-Virginian Province four-year assessment (1990-93). EPA/620/R-99/004. Office of Research and Development, U.S. EPA, Washington, DC 1999.

[18] Overton WS, White D, Stevens DL. Design report for EMAP. EPA/600/3-91/053. Office of Research and Development, U.S. EPA, Washington, DC 1990.

[19] Stevens DL. Variable density grid-based sampling designs for continuous spatial populations. Environmetrics 1997; 8: 167-95.

[20] State of Connecticut. Long Island Sound ambient water quality monitoring program, water quality and hydrographic surveys, standard operating procedures manual. Bureau of Water Management, Department of Environmental Protection, State of Connecticut, Hartford, CT 2000.

[21] U.S. EPA. A monitoring program for long island sound. The Long Island Sound Study, U.S. EPA, Stamford, CT 1994.

[22] Strobel CJ, Buffum HW, Benyi SJ, et al. Statistical summary: EMAP-estuaries Virginian Province - 1990-1993. EPA/620/R 94/026. U.S. EPA, Office of Research and Development, Washington, DC 1995.

[23] Strobel CJ, Buffum HW, Benyi SJ, Paul JF. Environmental monitoring and assessment program: Current status of Virginian Province (US) estuaries. Environ Monit Assess 1999; 56(1): 1-25.

[24] Stehman SV, Overton WS. Environmental sampling and monitoring. In: Patil GP, Rao CR, Eds. Handbook of statistics. Elsevier Science 1994; pp. 263-305.

[25] Morrison DF. Multivariate statistical methods, 2nd edition McGraw-Hill Book Co, New York 1976.

[26] Korndoerfer AL, Ed. Water quality monitoring networks. New Jersey Department of Environmental Protection, Trenton, NJ 1998.

[27] New Jersey Department of Environmental Protection. New Jersey ambient monitoring program, report on marine and coastal water 
quality 1990-1993. New Jersey Department of Environmental Protection, Office of Land and Water Planning, Trenton, NJ 1996.

[28] Texas A\&M University. Assessment of sediment contamination in Casco Bay, interpretive report and appendix A: Quality assurance data summaries. Technical Report \#92-157. Geochemical and Environmental Research Group and the Department of Oceanography, Texas A\&M University, College Station, TX 1992.

(C) Paul et al.; Licensee Bentham Open.

This is an open access article distributed under the terms of the Creative Commons Attribution License (http://creativecommons.org/licenses/by/2.5/), which permits unrestrictive use, distribution, and reproduction in any medium, provided the original work is properly cited. 